\title{
PLANEJAMENTO ESTRATÉGICO APLICADO A GESTÃO DAS CATEGORIAS DE BASE DO FUTEBOL
}

\author{
Carlos Roberto Franzini Filho (UAM) crfilho@anhembi.br \\ Alan Bruno Sales dos Santos (UAM) alan_kaka@ hotmail.com \\ Edivaldo Teme de Souza Jr. (UAM) eteme97@gmail.com \\ João Eduardo de Oliveira Sala (UAM) jdsala@ hotmail.com \\ Leonardo da Paixão Esposito (UAM) leopaes2904@gmail.com
}

Resumo: Embora o futebol seja o esporte mais popular no Brasil, o modelo de gestão de grande parte dos clubes do futebol brasileiro ainda é amador, sendo defasado em relação à maioria dos clubes do resto do mundo no processo de formação de jogadores profissionais. Por outro lado, o planejamento estratégico é fundamental para desenvolver uma visão de médio e longo prazo e, assim, conquistar os objetivos do negócio. Dentro desta abordagem, este trabalho tem por objetivo analisar o planejamento estratégico aplicado à gestão organizacional de um clube brasileiro com foco nas categorias de base e formação de atletas. Para atingir ao objetivo proposto, aplicou-se um estudo de caso exploratório com a coleta de dados a partir de uma entrevista com o atual diretor responsável pelo processo formação de atletas nas categorias de base do Sport Club Corinthians Paulista. As limitações para a realização deste trabalho apresentam-se com relação a análise de apenas único processo de formação de atletas profissionais em um único clube de futebol. Sugere-se como realização de pesquisas futuras, a extensão desta análise para outros clubes e a respectiva comparação dos modelos de gestão aplicados para as categorias de base.

Palavras-Chaves: Gestão Estratégica Organizacional, Planejamento Estratégico, Futebol, Categoria de Base, Sport Club Corinthians.

\section{Introdução}

O futebol é o esporte mais popular do mundo, porém não se sabe ao certo a data e onde surgiu. Alguns historiadores contam que anualmente os ingleses chutavam uma bola de couro representando o exército dinamarquês, para comemorar a expulsão da Dinamarca de seu país no século X, mas a prática virou popular e os jogos com bola passaram a ser realizados com maior frequência.

As primeiras regras para a prática do futebol foram escritas em 1830, onde estabeleceu-se o número de jogadores por equipe e os gols (onde a bola deve ser conduzida). Ao longo das 
décadas, novas regras foram implementadas e outras modificadas até chegar ao formato conhecido hoje, tendo sido sua profissionalização iniciada em 1885.

Zainaghi (1998) afirma que de forma incontestável, a introdução do futebol no Brasil dá-se em 1894 através de Charles Miller, que, ao retornar da Inglaterra, trouxe duas bolas.

Charles Miller, trouxe consigo além das bolas, roupas e regras para a prática do futebol no país. A qual foi realizada pela primeira vez pelo São Paulo Athletic Club, formado por colonos ingleses. Em 1923, a CBD (Confederação Brasileira de Desportos) foi filiada à FIFA, e o futebol brasileiro sofreu grandes modificações administrativas e estruturais para entrar em conformidade com as exigências da instituição, e apenas na década de 30 o futebol foi oficialmente profissionalizado no país. Logo o futebol se popularizou no Brasil, tornando-se o país com maior número de títulos mundiais (5), além de ter o principal jogador da história do futebol, Pelé.

Segundo Helal (1997), o futebol no Brasil pode ser visto como um poderoso instrumento de integração social. Através do futebol, a sociedade brasileira experimenta um sentido singular de totalidade e unidade, revestindo-se de uma universalidade capaz de mobilizar e gerar paixões em milhões de pessoas. É nesse universo que foi observado, com frequência, indivíduos cuja diversidade está estabelecida pelas normas econômicas e sociais da sociedade se transformarem em 'iguais' através de um sistema de comunicação que os leva a abraço e conversas informais nos estádios, ruas, praias e escritórios.

Outro fator de fundamental importância é o número de empregos gerados por todas as entidades envolvidas com o futebol no Brasil. Seja através dos clubes, das ligas, das federações, da Confederação, dos tribunais desportivos, que empregam diretamente, ou através da indústria, do comércio, da comunicação e outros meios que estão indiretamente envolvidos com o futebol, se trata de um grande polo empregatício.

Diante desse cenário econômico e social, o futebol tem inspirado empresas e investidores a tratá-lo como um negócio grandioso. Por ter se tornado uma necessidade indispensável do brasileiro, em parte também pelo poder da mídia, o futebol é considerado pelo mercado comercial como um produto altamente rentável. Portanto, investir neste ramo é garantia de grandes lucros como retorno.

"Em qualquer modalidade, o esporte profissional deve ser encarado não como veleidade esportiva, mas como atividade econômica. Entre negócios diretos e indiretos, ele movimentou US\$ 370 bilhões em 1997, segundo a Forbes, ou US\$ 1 bilhão por dia. Pela ordem: 1) o 
entretenimento é a maior indústria do mundo em volume de negócios e em número de empregos; 2) o esporte é o segundo maior segmento (depois do turismo) da indústria do entretenimento; 3) o futebol é o maior mercado da economia do esporte. Acabaram o amadorismo e o charlatanismo na condução do futebol” Destaca Joelmir Betting.

Atualmente existe grande fraqueza nos clubes de futebol na gestão organizacional de formação de atletas, mesmo o futebol não sendo uma ciência exata onde se faz estudos de lucro e prejuízos como em empresas para ter um dimensionamento, está comprovado que com uma boa estrutura organizacional e utilização de ferramentas robustas, aumenta as chances de que jogadores da base tenha sucesso atingindo o melhor potencial. Da mesma forma em que há estudos para a melhoria do físico e do potencial do jogador, tem a possibilidade de estudo para aumentar a qualidade de gestão e qualidade do clube com a engenharia de produção.

A engenharia de produção auxilia no aprimoramento do modelo de gestão utilizado (desde a procura de promessas, até virarem realidades profissionais, onde ajudarão a equipe dentro de campo e futuramente pode ocasionar sua venda com o aumento do poder financeiro do clube), mas como consequência, proporciona aos atletas maior desempenho/rendimento dentro e fora do campo com os fatores encontrados durante a pesquisa.

Diante das considerações iniciais, este trabalho tem por objetivo analisar o planejamento estratégico aplicado à gestão organizacional de um clube brasileiro com foco nas categorias de base e formação de atletas.

\section{Referencial teórico}

O conceito de estratégia abrange os diversos conjuntos de regras de decisões para orientar o comportamento de uma organização (ANSOFF, 1993), ou seja, compreende a determinação de metas básicas para longo prazo, os objetivos de uma empresa, a tomada de ações e o levantamento de recursos para alcançar as metas (CHANDLER, 1990, BUZZEL, 1977).

Dentro desta abordagem, o planejamento estratégico é uma das ferramentas mais utilizadas e aceitas pelos executivos em todo o mundo para avaliar o contexto da empresa e planejar o futuro das mesmas (RIGBY, 2001). O planejamento estratégico de uma organização tem por objetivo:

- identificar as ameaças e oportunidades, pontos fortes e fracos de uma organização;

- obter informações sobre mercado, indústria, concorrentes e da própria empresa; 
- reduzir os riscos das escolhas malfeitas;

- direcionar os negócios;

- analisar o macro ambiente e traçar objetivos e metas para toda a organização;

- preparar a empresa para enfrentar situação de crise;

- identificar informações relevantes e estrutura-las para decisão;

- assegurar o alcance de uma posição futura desejada através do planejamento de recursos;

- posicionar a empresa numa condição de liderança em relação aos seus principais concorrentes;

- induzir a elaboração e implantação de estratégias diferenciadas.

Dentro do futebol, observa-se as categorias de base como essenciais para os clubes, pois são responsáveis pela formação de atletas na modalidade, ensinando os fundamentos, embasamento teórico, refinando sua técnica e preparando o atleta psicologicamente para os desafios. Além disso, as categorias de base são uma forma de manter uma equipe de qualidade e um possível investimento que pode trazer retornos altíssimos. Para Ferreira e Paim (2011), a formação de atletas no Brasil foi por muito tempo espontânea e pouco trabalhada profissionalmente, porém, atualmente requer intervenção profissional e é um processo mais consciente e elaborado. Hoje a maioria dos clubes brasileiros contém departamentos de análise de desempenho e plano de ações para o desenvolvimento do atleta, analisando resultados e detectando com mais precisão o que deve ser lapidado.

O modelo de gestão de grande parte dos clubes do futebol brasileiro ainda é amador, sendo extremamente defasado em relação à maioria dos clubes do resto do mundo. O país que é referência de qualidade de jogadores, passa longe de ser exemplo quando o quesito é organização, responsabilidade, respeito aos seus principais clientes (torcedores), gerenciamento e tantos outros aspectos que estão ligados a gestão esportiva. Mesmo clubes que possuem uma excelente infraestrutura física, ainda não possuem um modelo de gestão capaz de extrair toda a potencialidade que as categorias de base podem gerar em prol da própria instituição.

O planejamento estratégico é fundamental para desenvolver uma visão de médio e longo prazo e, assim, conquistar os objetivos do negócio (MATOS et al, 2018), assim pode-se entender a interligação do projeto estratégico nas categorias de base, já que é um processo médio e longo prazo com duração de muitos anos até uma promoção do atleta ao profissional. 


\section{Metodologia}

A Figura 1 ilustra a estrutura metodológica considerada para atingir ao objetivo proposto com relação a natureza, abordagem, objetivo, método, técnicas de coleta e análise de dados.

Figura 1 - Estrutura metodológica do trabalho.

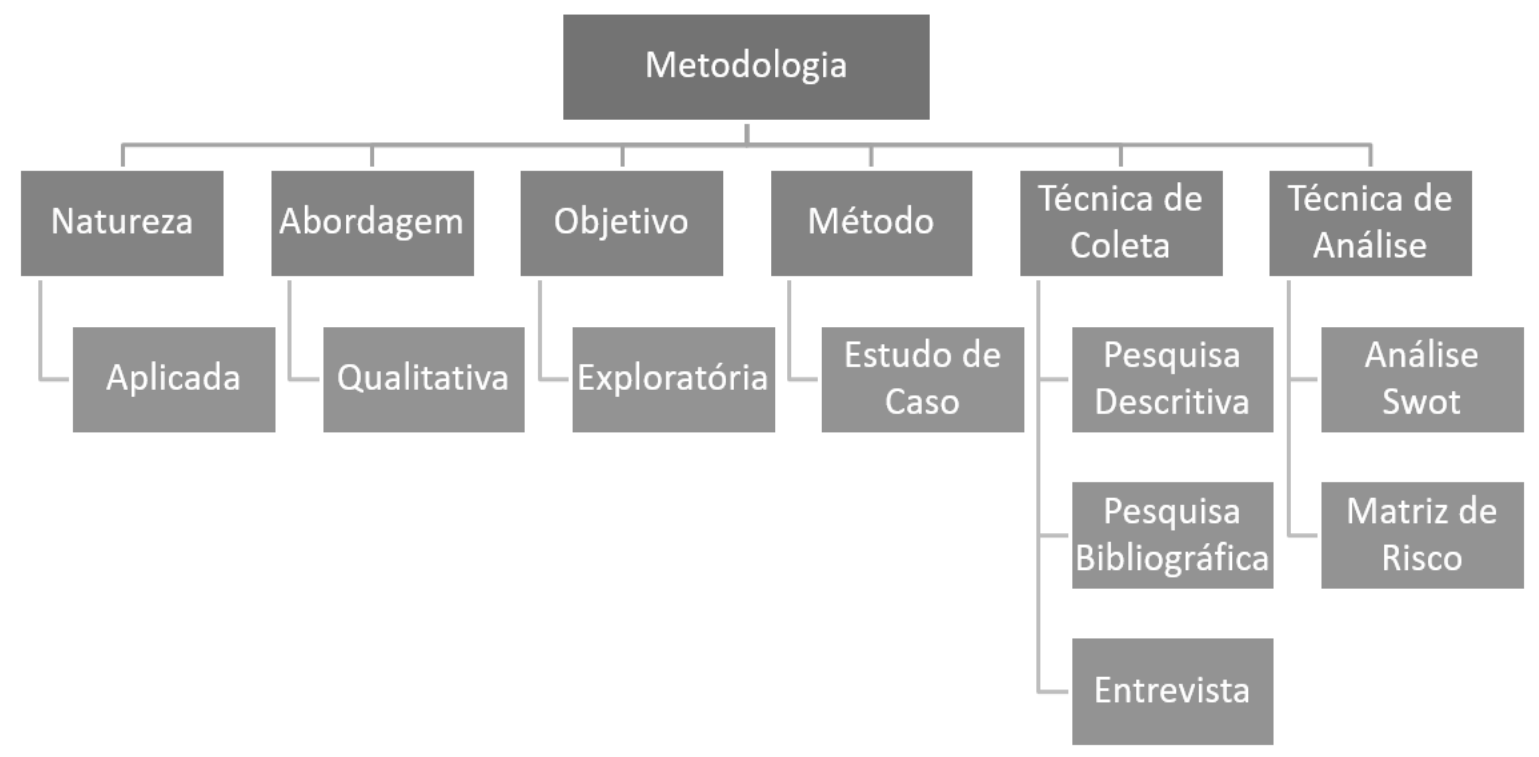

Fonte: Elaborado pelos autores (2020).

Com relação ao método, aplicou-se um estudo de caso exploratório que, segundo Nakano (2012), é uma pesquisa sem estruturação formal do método de pesquisa. Para Yin (2010), o estudo de caso é um estudo empírico que avalia acontecimentos atuais na conjuntura da vida real.

Para a coleta de dados realizou-se uma entrevista, que para Marconi e Lakatos (2010), é um encontro entre duas pessoas a fim de que uma delas obtenha informações a respeito de determinado assunto, mediante uma conversação de natureza profissional.

A técnica para análise dos dados coletados é a de análise de conteúdo. Bardin (1977) ressalta a importância do rigor na utilização da análise de conteúdo, a necessidade de ultrapassar as incertezas e descobrir o que é questionado. Ainda de acordo com Bardin (2011), a interpretação dos dados se deu pelo método análise de conteúdo, respaldada pelas observações in loco. As etapas da técnica orientadas por Bardin (2011) estão organizadas em três fases: 1) pré-análise, 2) exploração do material e 3) tratamento dos resultados, inferência e interpretação. 
Para concluir a análise, propôs-se uma matriz SWOT que avalia as forças e fraquezas de um processo e serve para posicionar ou verificar a situação e a posição estratégica da empresa no ambiente em que atua (MCCREADIE, 2008).

\section{Análise e discussão dos resultados}

O Sport Club Corinthians Paulista, objeto deste estudo, é um clube multiesportivo brasileiro da cidade de São Paulo-SP fundado como uma equipe de futebol no dia primeiro de setembro de 1910 por um grupo de operários do bairro Bom Retiro e sua torcida é considerada uma das maiores do mundo e atualmente estimada em 27 milhões de torcedores.

Para a coleta de dados a respeito da formação de atletas no Sport Club Corinthians, foi realizada uma entrevista semiestruturada no primeiro semestre de 2020 com o Diretor Carlos Roberto Auricchio, atual responsável pelo processo formação de atletas nas categorias de base do clube. Este processo de formação de atletas está ilustrado na Figura 2:

Figura 2 - Processo de formação de atletas de futebol.

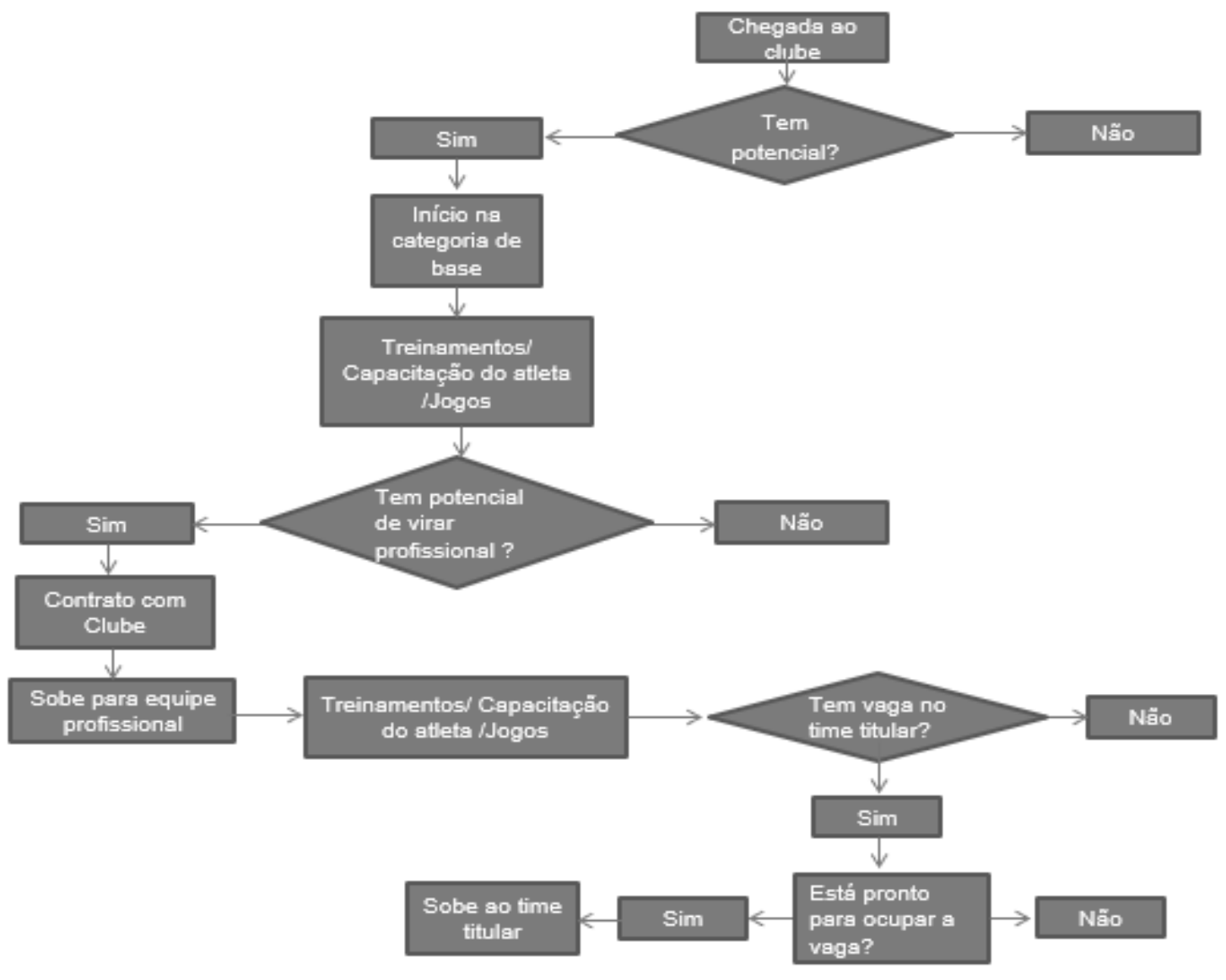

Fonte: Elaborado pelos autores (2020). 
Durante o processo de formação de jogadores ilustrado na Figura 2, existe a possibilidade de venda e/ou empréstimo do atleta. Por exemplo, se o jogador tiver um bom desempenho e se destacar na equipe principal, haverá outros clubes interessados na contratação definitiva ou por empréstimo, o que pode contribuir para o seu desenvolvimento profissional.

Observa-se no Quadro 1, o resultado da entrevista com o Diretor Carlos Roberto Auricchio, atual responsável pelo processo formação de atletas nas categorias de base do clube.

Quadro 1 - Entrevista com Diretor responsável pelas categorias de base do Sport Club Corinthians Paulista.

\begin{tabular}{|c|c|}
\hline Perguntas & Análise/Respostas \\
\hline $\begin{array}{l}\text { Com qual frequência é realizada } \\
\text { planejamento para organização da base? }\end{array}$ & Segundo o diretor das categorias de base, o planejamento é anual. \\
\hline $\begin{array}{l}\text { Este planejamento é realizado por } \\
\text { quantas pessoas? E quais suas funções? }\end{array}$ & $\begin{array}{l}\text { Segundo o entrevistado, normalmente pelos diretores, juntamente com o gerente } \\
\text { e coordenadores das categorias, em torno de seis pessoas, logo em seguida } \\
\text { passamos ao departamento de comissões. }\end{array}$ \\
\hline $\begin{array}{l}\text { Esta sala de analistas com estes } \\
\text { funcionários corresponde para atletas do } \\
\text { clube e atletas de outros clubes? }\end{array}$ & $\begin{array}{l}\text { O questionado responde que filmam todos os nossos treinos e jogos, passando } \\
\text { detalhado, os dados sobre o time do clube e sobre os adversários ao } \\
\text { departamento de comissões. }\end{array}$ \\
\hline $\begin{array}{l}\text { Quantos funcionários, sem contar os } \\
\text { jogadores trabalham na categoria de } \\
\text { base? }\end{array}$ & $\begin{array}{l}\text { Segundo o entrevistado, o clube tem em torno de } 120 \text { pessoas na categoria de } \\
\text { base. }\end{array}$ \\
\hline $\begin{array}{l}\text { Qual investimento nas categorias de base } \\
\text { em média? }\end{array}$ & $\begin{array}{l}\text { Segundo o diretor das categorias de base, as despesas giram em torno de } \mathrm{R} \$ \\
1.200 .000,00 \text { reais mensalmente. O orçamento do clube estimado no ano de } \\
2019 \text { era de } \mathrm{R} \$ 19.000 .000,00 \text { reais e foi gasto } \mathrm{R} \$ 14.000 .000,00 \text { reais, } \\
\text { encerrando o ano com superávit. }\end{array}$ \\
\hline $\begin{array}{l}\text { Qual o número de atletas total do sub } 11 \\
\text { ao sub 20? }\end{array}$ & O entrevistado informou que existe em torno 200 atletas. \\
\hline $\begin{array}{l}\text { Em média, qual porcentagem dos atletas } \\
\text { do sub } 11 \text { ao Sub } 20 \text { são do clube? }\end{array}$ & $\begin{array}{l}\text { Segundo o entrevistado, não depende da categoria e sim dos negócios que são } \\
\text { feitos com atletas de outros clubes. "Exemplo: se nos interessar um jogador do } \\
\text { Guarani, independente da idade temos que negociar uma porcentagem para ficar } \\
\text { no clube de origem, ou pagar o valor que eles queiram. As categorias menores, } \\
\text { sub } 11 \text { e } 13 \text { quase todos } 100 \% \text { e as demais alternam entre } 10 \% \text { a } 100 \% . "\end{array}$ \\
\hline $\begin{array}{l}\text { Como são feitos recurso de captação de } \\
\text { atletas (apenas peneiras) ou tem outra } \\
\text { maneira como olheiros entre outros? }\end{array}$ & $\begin{array}{l}\text { O entrevistado responde que hoje dificilmente consegue algum jogador em } \\
\text { peneiras feitas no clube, é procurado pelo país a fora, para testes ou nos outros } \\
\text { campeonatos, ou até mesmo observar os adversários e negociar. O clube tem } \\
\text { uma equipe de } 10 \text { captadores que olham e trazem para os analistas. }\end{array}$ \\
\hline $\begin{array}{l}\text { São vendidos atletas ainda na categoria } \\
\text { de base? Se sim, o valor é revertido para } \\
\text { a base? }\end{array}$ & $\begin{array}{l}\text { Segunda o diretor das categorias de base os jogadores não são vendidos } \\
\text { enquanto estão na base,primeiro o jogador é levado para a equipe pricipal para } \\
\text { fazer a venda, mesmo que recebam prospostas. }\end{array}$ \\
\hline $\begin{array}{l}\text { Em média, qual o número de jogadores } \\
\text { que são profissionalizados? E quantos } \\
\text { são incluídos na equipe principal do } \\
\text { Corinthians anualmente? }\end{array}$ & $\begin{array}{l}\text { Segundo o entrevistado, a partir de } 16 \text { anos, é chamdo o atleta para fazer um } \\
\text { contrato profissional, e normalmente uma média de três ou quatro são incluídos } \\
\text { na equipe de cima, depende da coragem do treinador que lá está. "No final de } \\
2019 \text {, por exemplo, subiu nove jogadores, mas como o elenco dos profissionais } \\
\text { estava inchado emprestaram metade deles." }\end{array}$ \\
\hline $\begin{array}{l}\text { Alguma porcentagem de jogadores da } \\
\text { base vendidos profissionalmente são } \\
\text { revertidos para o departamento amador? }\end{array}$ & $\begin{array}{l}\text { Segundo o entrevistado, não há porcentagem revertida para o departamento } \\
\text { amador, "temos a conviç̧ão que deveria, não propriamente o dinheiro e sim } \\
\text { contabilizar para base, mas ainda não é assim." }\end{array}$ \\
\hline
\end{tabular}

Fonte: Elaborado pelos autores (2020). 
A Figura 3 apresenta o ranking dos clubes que mais utilizaram os atletas formados por suas categorias de base na equipe profissional durante os jogos realizados entre 2015 e 2019. Este levantamento leva em consideração os minutos jogados por atletas da base na equipe principal.

Figura 3 - Ranking de utilização pelos clubes de atletas formados em suas categorias bases.

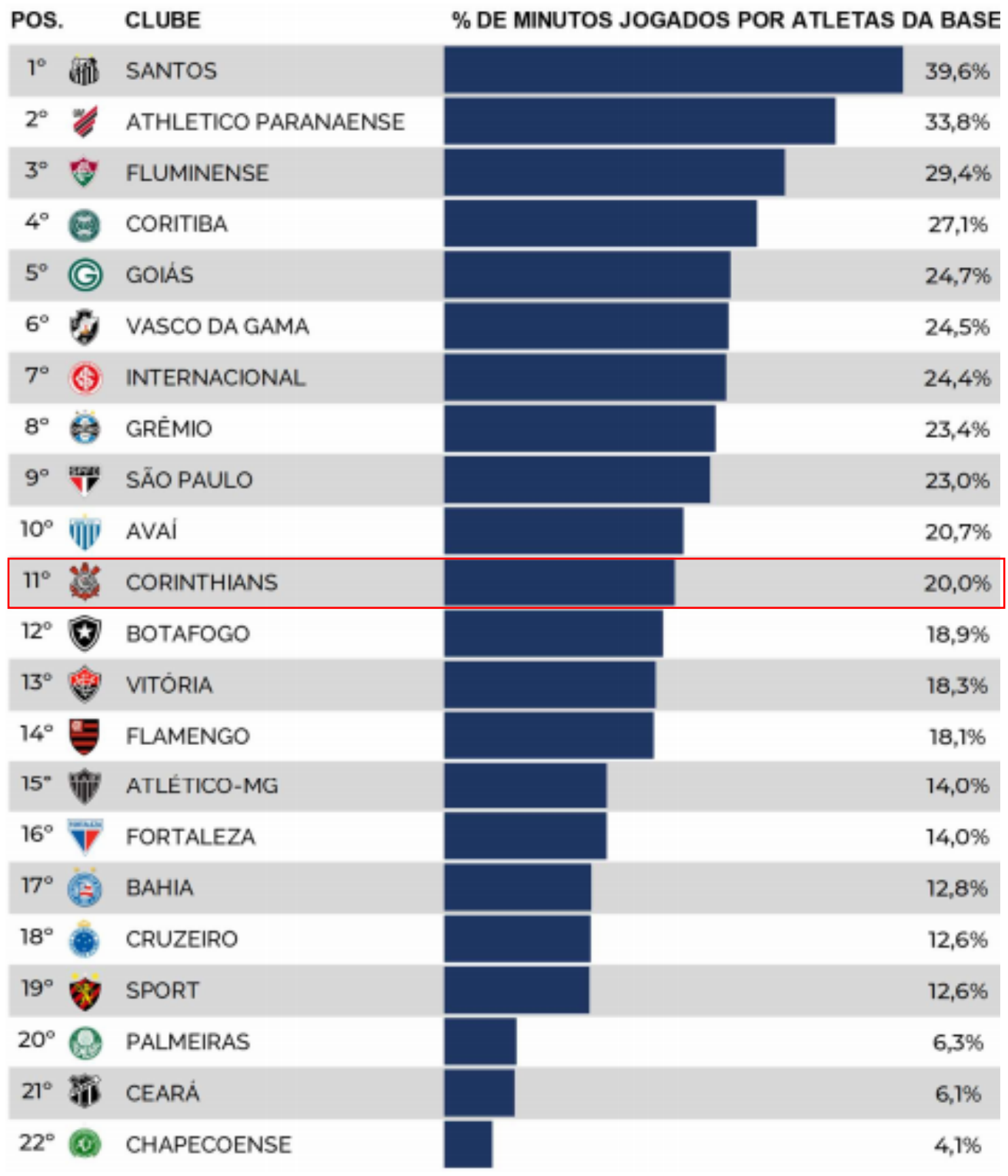

Fonte: Adaptado de PLURI Consultoria (2019).

No caso do Corinthians, o clube se encontra em $11^{\circ}$ (décimo primeiro) com $20 \%$ dos minutos jogados por atletas revelados pelo clube. Conforme apurado na entrevista, em média três ou quatro jogadores são incluídos na equipe de cima anualmente, porém depende da coragem do treinador para colocá-los em campo. No caso de 2019, por exemplo, devido à grande quantidade de atletas no elenco profissional, houve um empréstimo dos recém promovidos para outras equipes para adquirirem experiência e assim ocorre com a grande parte dos atletas 
recém promovidos. Porém, uma pequena quantidade desses "emprestados" retornam para o clube e se destacam. Dessa forma ocasionando um retorno muito abaixo do que deveria, tanto financeiramente, quanto na ajuda para possíveis títulos.

Dentro desta abordagem, propõe-se uma matriz SWOT ilustrada na Figura 4 para avaliar as forças e fraquezas de um processo e serve para posicionar ou verificar a situação e a posição estratégica do clube no que diz respeito a formação de atletas profissionais.

Figura 4 - Análise SWOT.

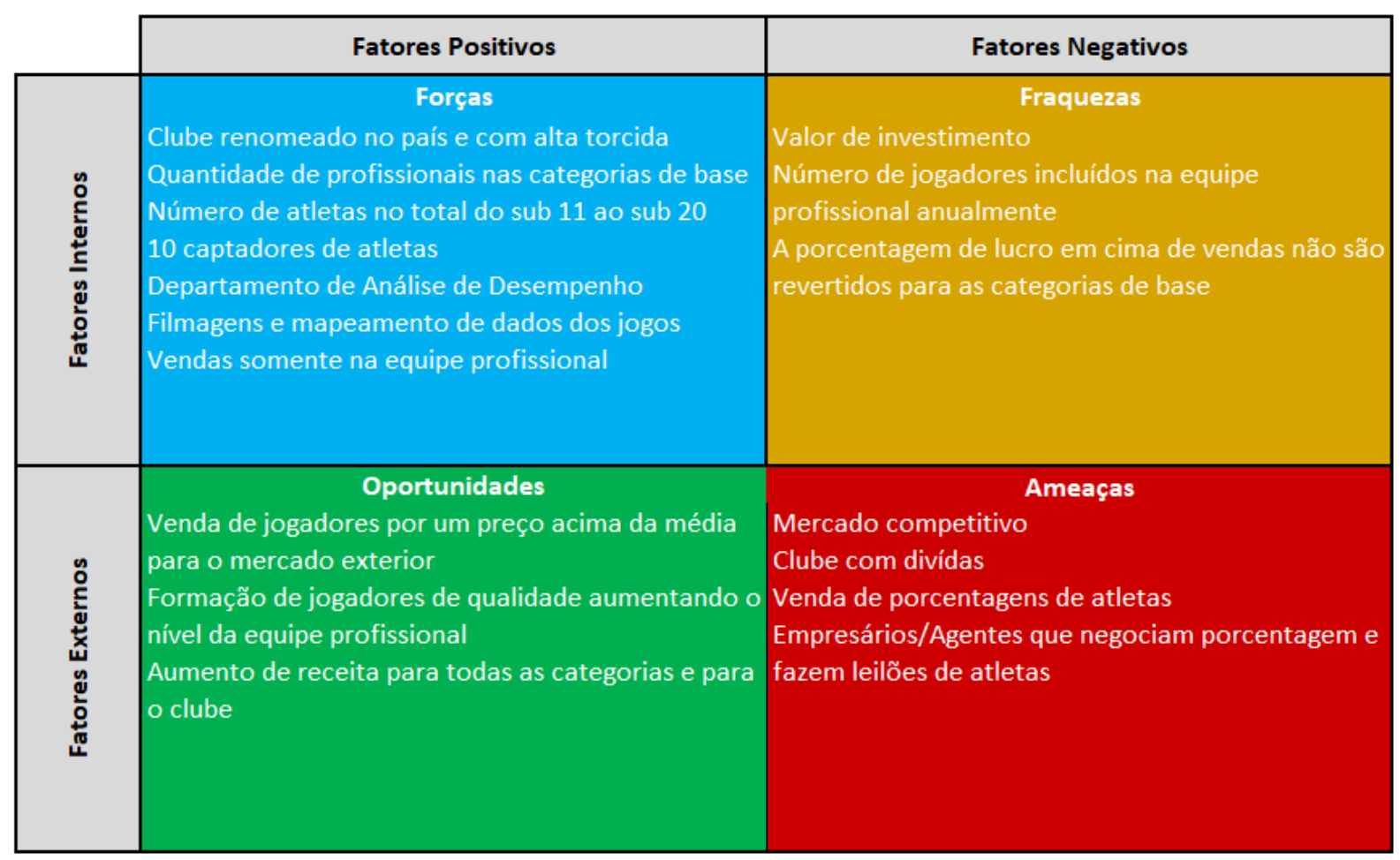

Fonte: Elaborado pelos autores (2020).

O primeiro ponto positivo foi a força do clube, o Sport Club Corinthians Paulista é um dos maiores clubes do país e do mundo. na entrevista identificou-se a quantidade de profissionais e atletas nas categorias do clube e foi considerado um bom número para o trabalho feito. $\mathrm{Na}$ entrevista foi dito sobre o departamento de análise de desempenho e captação o que é considerado uma força do clube que é estruturado nesse departamento contando com filmagens e mapeamento dos dados dos atletas, por último, o entrevistado relatou que os atletas hoje só são vendidos quando estão na categoria profissional, outro ponto positivo considerando a realidade do país onde atletas são negociados antes de chegar ao profissional sem a oportunidade de mostrar seu futebol ao treinador profissional.

Nas fraquezas, o valor investido, considerando que hoje é um valor alto para pouco retorno já que o clube revelou pouquíssimos atletas nos últimos anos e isso se dá também a falta de oportunidade aos atletas, sendo que poucos são promovidos a equipe profissional, foi 
estimado que o valor investido deve ser uma porcentagem dos lucros com as vendas e consequentemente com o alto de oportunidades terá aumento de lucro e aumento de investimento.

Em oportunidades, tem um mercado exterior em constante alta e com olhos no mercado brasileiro, é uma grande oportunidade de retorno financeiro. A formação de atletas de qualidade aumenta o potencial da equipe também em campo podendo resultar em conquistas e maior lucro em vendas de produtos, bilheteria, premiações e consequentemente do valor do clube.

Existem algumas ameaças que o clube precisa estar atento para obter resultado positivo. O mercado é muito competitivo, e com o clube não pode perder tempo nas suas ações e em atualizações de ferramentas que o mercado disponibilizar. O clube tem muitas dívidas de forma geral e muita receita pode entrar para cobrir esse tipo de "déficit" ao invés de investir, e não é recomendado a venda de porcentagem de atletas para agentes e empresários onde se pode perder altos lucros como nos casos do Vinicius Junior e o Lucas Paquetá, além disso, esses empresários acabam fazendo leilões dos atletas só visando lucro.

Os principais riscos para o processo de formação de atletas profissionais pelos clubes estão descritos no Quadro 2.

Quadro 2 - Riscos para o processo de formação de atletas nas categorias de base dos clubes.

\begin{tabular}{|l|l|}
\hline \multicolumn{2}{|c|}{ Riscos } \\
\hline $\mathbf{1}$ & O empresario se apossar do jogador revelado pelo clube \\
\hline $\mathbf{2}$ & O jogador desistir de ser profissional \\
\hline $\mathbf{3}$ & O jogador receber uma proposta de outro clube \\
\hline $\mathbf{4}$ & O jogador se lesionar \\
\hline $\mathbf{5}$ & O jogador demonstrar pouca evolução \\
\hline
\end{tabular}

Fonte: Elaborado pelos autores (2020).

A partir da análise SWOT, foi elaborada uma matriz de risco ilustrada na Figura 5, onde é possível analisar o impacto e a probabilidade de algumas situações ocorrerem, prejudicando a formação do atleta.

Figura 5 - Análise SWOT.

\begin{tabular}{|c|c|c|c|c|c|c|}
\hline \multirow{2}{*}{\multicolumn{2}{|c|}{ Matriz de Risco }} & \multicolumn{5}{|c|}{ Impacto } \\
\hline & & Sem Impacto & Leve & Médio & Grave & Gravíssimo \\
\hline \multirow{5}{*}{$\begin{array}{l}\frac{0}{0} \\
\frac{10}{0} \\
\frac{10}{0} \\
\frac{0}{10} \\
\frac{0}{0} \\
\frac{1}{2}\end{array}$} & Quase Certo & & & & & 3 \\
\hline & Alta & & & & 1 & \\
\hline & Média & & & & 4 & 5 \\
\hline & Baixa & & & 2 & & \\
\hline & Raro & & & & & \\
\hline
\end{tabular}

\begin{tabular}{|l|l|}
\hline \multicolumn{2}{|l|}{ Legenda } \\
\hline & Risco Moderado \\
\hline & Risco Elevado \\
\hline & Risco Extremo \\
\hline & Risco Baixo \\
\hline
\end{tabular}

Fonte: Elaborado pelos autores (2020). 
Com relação ao impacto e a probabilidade classificados na Figura 5 para os riscos apurados, observa-se que exceto o risco 2 (o jogador desistir do processo de formação profissional) que está classificado como moderado, todos os demais estão classificados como risco extremo, ou seja, com probabilidade alta e impacto gravíssimo. Diante deste cenário, propõe-se o plano de Ação descrito no Quadro 3 para mitigar os riscos.

Quadro 3 - Plano de ação para os riscos.

\begin{tabular}{|c|c|c|}
\hline \multicolumn{3}{|r|}{ Plano de Ação } \\
\hline Risco & Status Matriz & Plano de Ação \\
\hline $\begin{array}{l}\text { O empresário se apossar do jogador revelado pelo } \\
\text { clube }\end{array}$ & Risco Extremo & $\begin{array}{l}\text { Dar poucos espaços aos empresários no clube e orientando sempre o atleta ao conversar } \\
\text { com os superiores se estiver descontente com algo. }\end{array}$ \\
\hline O jogador desistir de ser profissional & Risco Moderado & $\begin{array}{l}\text { O clube irá dar suporte para o atleta e sua familia, monitorando o máximo possível da sua } \\
\text { situação e estimulando sempre o mesmo, com acompanhamento psicológico no dia a dia. }\end{array}$ \\
\hline O jogador receber uma proposta de outro clube & Risco Extremo & $\begin{array}{l}\text { Estimular o atleta e apoiar na sua vida pessoal, tornando um ambiente agradável e seguro } \\
\text { onde ele queira fica e analisar o grau de relevância do atleta negociando a proposta. }\end{array}$ \\
\hline O jogador se lesionar & Risco Extremo & $\begin{array}{l}\text { Acompanhamento e investimento no setor de fisiologia, contando com ferramentas e } \\
\text { profissionais de alta qualidade para monitoramento físico. }\end{array}$ \\
\hline O jogador demonstrar pouca evolução & Risco Extremo & $\begin{array}{l}\text { Conversar com o jogador caso algo extra campo esteja influenciando no seu crescimento e } \\
\text { continuar o monitoramento de evolução o mais preciso possível. }\end{array}$ \\
\hline
\end{tabular}

Fonte: Elaborado pelos autores (2020).

As ações propostas no Quadro 3 não foram apresentadas ao clube por falta de oportunidade em razão do atual cenário de distanciamento social por motivo da pandemia. Espera-se em um futuro próximo discutir estas ações com o Diretor responsável pelo processo de formação de atletas profissionais do clube.

\section{Considerações finais}

O objetivo proposto para este trabalho foi analisar o planejamento estratégico aplicado à gestão organizacional de um clube brasileiro com foco nas categorias de base e formação de atletas. Como resultado desta análise, conclui-se que que o Sport Club Corinthians tem alto potencial para a formação de atletas e tem uma boa base administrativa para isso, porém necessita de ferramentas e um planejamento robusto, contendo investimentos em departamentos de psicologia e fisiologia e monitorando seus produtos (jogadores) para que esse caminho de evolução do atleta na base até o profissional, não possa ser destruído ou caso se tenha sucesso, os benefícios para o clube sejam altos, como na venda de porcentagem de atletas. 
As limitações para a realização deste trabalho apresentam-se com relação a análise de apenas único processo de formação de atletas profissionais em um único clube de futebol. Em razão das categorias de base impactarem significativamente no desempenho financeiro de um clube de futebol, espera-se que a realização deste trabalho possa contribuir como incentivo para adoção do planejamento estratégico pelos clubes de futebol na formação de atletas profissionais. Os clubes de futebol possuem grande potencial e aspectos positivos demonstrados na análise SWOT, porém foi mencionado como um clube de futebol enfrenta diversos obstáculos na formação dos seus atletas profissionais.

Sugere-se como realização de pesquisas futuras, a extensão desta análise para outros clubes e a respectiva comparação dos modelos de gestão aplicados para as categorias de base.

\section{Agradecimentos}

Os agradecimentos à Universidade Anhembi Morumbi pelo apoio e incentivo a pesquisa, seu corpo docente, administração e coordenação do curso de Engenharia de Produção. Os agradecimentos ao Sport Club Corinthians Paulista pelas informações e ao diretor das categorias de base Carlos Roberto Auricchio pela entrevista concedida. 


\section{REFERÊNCIAS}

ANSOFF, Igor H; McDONNELL, Edward J.; Implantando a administração estratégica, São Paulo, Atlas, 1993.

BARDIN L. L'Analyse de contenu. Editora: Presses Universitaires de France, 1977. Análise de conteúdo. SP: Edições 70, 2011.

BUZZELL, R.D. et a. Strategic marketing management. Boston: Harvard University, Graduate School of Business Administration, 1977.

CHANDLER, Jr. Alfred D. Strategy and Structure: Chapters in the history of the American Industrial Enterprise, Cambridhge, Massachusets: The MIT Press, 1990.

Ferreira, D. P., \& Paim, M. C. C. (2011). Estruturação das categorias de base no futebol. EFDeportes.com, 158. Disponível em: 〈http://goo.gl/n8CbcP> Acesso em: 22 abr. 2020.

HELAL, Ronaldo. Passes e impasses: futebol e cultura de massa no Brasil. Vozes, 1997.

MARCONI, M. De A.; LAKATOS, E. M. Técnicas de pesquisa. São Paulo: Atlas, 2007.

NAKANO, D. Métodos de pesquisa adotados na Engenharia de Produção e gestão de operações. In: MIGUEL, P.A.C. (Coord.). Metodologia de pesquisa em Engenharia de Produção e Gestão de Operações. 2. ed. São Paulo: Elsevier, 2012.

MATOS, Celso Augusto de et al. Os Efeitos do Alinhamento entre Práticas de Marketing e Estratégia de Negócios no Desempenho das Empresas. Revista Brasileira de Marketing, v. 17, n. 6, p. 849-865, 2018.

MCCREADIE, Karen. A Arte da Guerra SUN TZU: uma interpretação em 52 ideias brilhantes: 1. ed. São Paulo: Globo, 2008.

RIGBY, Darrell K. Management tools 2001: global results: Annual survey of senior executives. Bain \& Company, Inc., 2001. 2002.

PLURI Consultoria. Categorias de base no Brasil. São Paulo, 2020. Disponível em: < https://www.pluriconsultoria.com.br/wp-content/uploads/2020/02/Categorias-de-Base-noBrasil.pdf> Acesso em: 24 mai. 2020.

ZAINAGHI, Domingos Sávio. Os atletas profissionais de futebol no direito do trabalho. São Paulo: LTr, 1998. 